Western University

Scholarship@Western

$5-1-2020$

\title{
Towards the assessment of quality of life in patients with disorders of consciousness
}

\author{
Jasmine Tung \\ Western University \\ Kathy N. Speechley \\ Western University \\ Teneille Gofton \\ Western University \\ Laura E. Gonzalez-Lara \\ Western University \\ Mackenzie Graham \\ University of Oxford
}

See next page for additional authors

Follow this and additional works at: https://ir.lib.uwo.ca/brainscanpub

\section{Citation of this paper:}

Tung, Jasmine; Speechley, Kathy N.; Gofton, Teneille; Gonzalez-Lara, Laura E.; Graham, Mackenzie; Naci, Lorina; Peterson, Andrew H.; Owen, Adrian M.; and Weijer, Charles, "Towards the assessment of quality of life in patients with disorders of consciousness" (2020). BrainsCAN Publications. 4.

https://ir.lib.uwo.ca/brainscanpub/4 


\section{Authors}

Jasmine Tung, Kathy N. Speechley, Teneille Gofton, Laura E. Gonzalez-Lara, Mackenzie Graham, Lorina Naci, Andrew H. Peterson, Adrian M. Owen, and Charles Weijer 


\title{
Towards the assessment of quality of life in patients with disorders of consciousness
}

\author{
Jasmine Tung ${ }^{1}\left(\right.$ ) Kathy N. Speechley ${ }^{1,2,3} \cdot$ Teneille Gofton $^{4} \cdot$ Laura E. Gonzalez-Lara $^{5} \cdot$ Mackenzie Graham $^{6}$. \\ Lorina Naci $^{7,8}$ • Andrew H. Peterson ${ }^{9} \cdot$ Adrian M. Owen ${ }^{5,10}$. Charles Weijer ${ }^{1,5,10}$
}

Accepted: 7 December 2019 / Published online: 14 December 2019

(c) Springer Nature Switzerland AG 2019

\begin{abstract}
Purpose To generate foundational knowledge in the creation of a quality-of-life instrument for patients who are clinically diagnosed as being in a vegetative or minimally conscious state but are able to communicate by modulating their brain activity (i.e., behaviourally nonresponsive and covertly aware). The study aimed to identify a short list of key domains that could be used to formulate questions for an instrument that determines their self-reported quality of life.

Methods A novel two-pronged strategy was employed: (i) a scoping review of quality-of-life instruments created for patient populations sharing some characteristics with patients who are behaviourally nonresponsive and covertly aware was done to compile a set of potentially relevant domains of quality of life; and (ii) a three-round Delphi consensus process with a multidisciplinary panel of experts was done to determine which of the identified domains of quality of life are most important to those who are behaviourally nonresponsive and covertly aware. Five expert groups were recruited for this study including healthcare workers, neuroscientists, bioethicists, quality-of-life methodologists, and patient advocates.

Results Thirty-five individuals participated in the study with an average response rate of $95 \%$ per round. Over the three rounds, experts reached consensus on 34 of 44 domains (42 domains were identified in the scoping review and two new domains were added based on suggestions by experts). 22 domains were rated as being important for inclusion in a qualityof-life instrument and 12 domains were deemed to be of less importance. Participants agreed that domains related to physical pain, communication, and personal relationships were of primary importance. Based on subgroup analyses, there was a high degree of consistency among expert groups.

Conclusions Quality of life should be a central patient-reported outcome in all patient populations regardless of patients' ability to communicate. It remains to be determined how covertly aware patients perceive their circumstances and quality of life after suffering a life-altering injury. Nonetheless, it is important that any further dialogue on what constitutes a life worth living should not occur without direct patient input.
\end{abstract}

Keywords Quality of Life · Brain injury · Disorders of consciousness · Communication disorder · Delphi method · Bioethics

Jasmine Tung

jtung26@uwo.ca

1 Department of Epidemiology and Biostatistics, Western University, London, ON, Canada

2 Children's Health Research Institute, Lawson Health Research Institute, London, ON, Canada

3 Department of Pediatrics, Western University, London, ON, Canada

4 Department of Clinical Neurological Sciences, Western University, London, ON, Canada

5 Brain and Mind Institute, Western University, London, ON, Canada
6 Oxford Uehiro Centre for Practical Ethics, University of Oxford, Oxford, UK

7 School of Psychology, Trinity College Dublin, Dublin, Ireland

8 Global Brain Health Institute, Trinity College Dublin, Dublin, Ireland

9 Institute for Philosophy and Public Policy, George Mason University, Fairfax, USA

10 Rotman Institute of Philosophy, Western University, London, ON, Canada 


\section{Introduction}

Brain injury is a leading cause of death and disability worldwide [1]. More than five million people in the United States are currently living with long-term disability as a result of an acquired brain injury [2]. A subset of those who are severely brain injured will enter a state of impaired consciousness, also known as a disorder of consciousness, as a result of their injury. Categories of disorders of consciousness include coma, vegetative state, and minimally conscious state [3]. Patients suffering from disorders of consciousness can be left profoundly disabled and bedridden with permanent motor, cognitive, and speech impairments.

Currently, little is known about the welfare and quality of life $(\mathrm{QoL})$ of these patients because their injuries impair communication. Previous research examining physician and public perceptions of the QoL of patients in a vegetative or minimally conscious state shows that the majority of respondents fail to see how these lives could be worth living [4]. Understanding QoL from the perspective of brain-injured patients with profound communication impairments would provide insight into how satisfied these patients are with their existence. Patient-reported QoL could also be used to help families and health care providers in decision making regarding treatment, rehabilitation, and withdrawal of life-sustaining treatments.

Recently, functional magnetic resonance imaging (fMRI) techniques have emerged as tools for detecting intact cognitive abilities in select patients who have been diagnosed as being in a vegetative or minimally conscious state [5]. The first patient in a vegetative state discovered to be covertly aware was able to willfully modulate her brain activity by following verbal commands while being scanned in an fMRI [6]. Following this study, researchers used an imagery paradigm to establish communication with some of these patients through the use of "yes" or "no" questions [7]. Additional patients diagnosed as vegetative or minimally conscious have been able to successfully communicate using this imagery paradigm [7-9]. A meta-analysis of six studies demonstrated that 42 of 292 disorder-of-consciousness patients who were unresponsive at the bedside could modulate their brain activity to follow commands [10]. All of these patients had a clinical diagnosis that did not reflect the true nature of their awareness or cognitive ability. To describe this unique subset of patients who are covertly conscious but unable to communicate at the bedside, the term "behaviourally nonresponsive and covertly aware" will be used here.

The ability to directly communicate with select patients with disorders of consciousness provides an opportunity to gather self-reported QoL information. Yet, many challenges remain in defining and measuring QoL in this population that must be addressed before such insight can be obtained. QoL is defined by the World Health Organization as "the individual's perception of their position in life in the context of the culture and value systems in which they live, and in relation to their goals, expectations, standards, and concerns." [11] However, there is a lack of information on what criteria patients who are behaviourally nonresponsive and covertly aware use to evaluate their QoL. First, this poses a challenge in creating or administering an existing QoL instrument because it remains to be determined which domains should be included when assessing QoL in these patients. Second, due to the profound disabilities experienced by these patients, traditional techniques used to develop QoL instruments cannot be used. Specifically, challenges with the development of a QoL instrument for patients who are behaviourally nonresponsive and covertly aware include the limited ability to interview patients to inform question development; the brain-computer interface allowing only "yes" or "no" questions to be posed; and the small number of questions that can be asked during an fMRI scanning session due to response fatigue in brain-injured patients. These circumstances present obstacles that have not been navigated by any developers of existing QoL instruments and require a novel approach.

This study was conducted to generate foundational knowledge for the creation of an instrument to assess QoL in patients who are behaviourally nonresponsive and covertly aware. The aim of the study was to identify a short list of key domains of QoL, through an innovative two-step approach. These domains could then be used to formulate questions for a self-reported QoL instrument that could be administered to patients who are behaviourally nonresponsive and covertly aware using fMRI.

\section{Methods}

The methodology for this study was adapted from the work of Pietersma et al. who used a modified Delphi consensus process to identify the essential domains of health-related QoL for a nonspecific patient population [12]. Here, a novel two-step strategy was employed to identify the key domains of QoL that are relevant to the creation of a QoL instrument for behaviourally nonresponsive and covertly aware individuals. This included (i) a scoping review of QoL instruments created for patient populations sharing some characteristics with patients who are behaviourally nonresponsive and covertly aware; and (ii) a three-round Delphi consensus process with a multidisciplinary panel of experts.

Approval for this study was obtained from the Western University Health Science Research Ethics Board 
(\#108066). The Delphi consensus process was undertaken from September to December 2016. Informed consent was obtained from all participants in the study.

\section{Scoping Review of Relevant QoL Instruments}

A scoping review was conducted to identify a set of potentially relevant domains of QoL for patients who are behaviourally nonresponsive and covertly aware. The search identified existing QoL instruments designed to be administered in patient populations with some similarities to patients who are behaviourally nonresponsive and covertly aware, namely those with neurological or neurodegenerative conditions (e.g., Parkinson disease, amyotrophic lateral sclerosis); physical disabilities (e.g., quadriplegia, locked-in syndrome); cognitive impairments (e.g., dementia, Down syndrome, autism); or brain injury. The research team reasoned that domains used by researchers to evaluate QoL in similar patient populations with lifechanging injuries have the potential to accurately capture QoL in patients who are behaviourally nonresponsive and covertly aware.

The electronic databases Health and Psychosocial Instruments, PsycTests, and Mental Measurement Yearbook were searched for published QoL instruments using the following keywords: (1) quality of life OR well-being; (2) neurological OR neurodegenerative OR disability OR cognitive OR trauma OR brain injury; (3) \#1 AND \#2. Two levels of screening were performed to assess relevance, including title/abstract and full-text review. To meet the criteria for inclusion, a QoL instrument needed to (a) be designed for the aforementioned patient populations; (b) employ a multidimensional and broad definition of QoL so not to limit or omit crucial areas of well-being; (c) be developed for completion by adult patients and not proxies, children, or caregivers; and (d) be available in English.

The search identified a total of 949 QoL instruments (939 after the removal of duplicates). Titles and abstracts were reviewed, yielding 172 instruments for full-text analysis. 51 instruments met the pre-specified inclusion criteria. Each instrument identified was examined and the domains used to evaluate QoL were abstracted. A total of 448 domains of quality of life were extracted. The domains from each instrument were organized and refined by the research team into one of the following categories: physical, mental, social, psychosocial, economic, overall QoL, or other. A description was then generated for each domain by consulting the documentation for the original instrument from which the domain was abstracted. In the end, 42 distinct domains of QoL were identified from the instruments that were included in the review (Table 1), and these were used to inform the first-round survey for the Delphi consensus process.

\section{Delphi consensus process}

The Delphi consensus technique involves the systematic gathering of information from participants within their domain of expertise, using a series of purposefully designed surveys, with the goal of reaching a convergence of opinion [13]. After each round, results are summarized and fed back to participants, prior to the dissemination of the next survey. This process allows the experts to reassess their original answers and possibly change their opinion in the next round [13]. The anonymity of the feedback process gives participants the equal opportunity to express ideas in an unbiased fashion, and all opinions are weighted equally [14]. In the Delphi process, participants are referred to as experts because they possess expertise in areas that are of interest to the researchers [14].

This study used a three-round Delphi process with three online surveys. Experts who consented to participate were emailed links to each survey and given a 2 -week deadline to complete it. Only those who participated in the first survey were sent the second and third iteration of the survey. After each round, results were analyzed and a summary report with aggregate data and anonymized participant information was emailed to participants. Experts were given the opportunity to see how other participants responded and reflect on their own responses before completing the next survey.

\section{Recruitment of participants}

Five expert groups were recruited for this study: (a) healthcare personnel who have worked closely with patients in a vegetative or minimally conscious state for at least 1 year prior to this study; (b) neuroscientists actively conducting research into patients with disorders of consciousness; (c) bioethicists with expertise in patient well-being who have published on welfare or disorders of consciousness or are on the editorial board of a prominent journal relevant to wellbeing or bioethics; (d) quality-of-life methodologists with experience in developing and evaluating measures of QoL who have published research on QoL or are on the editorial board of a prominent QoL journal; and (e) patient advocates who were either caregivers of patients in a vegetative or minimally conscious state or who had themselves recovered from a disorder of consciousness.

An adaptation of the Borgiel method was used for recruitment [15]. Research team members who have experience working with patients with disorders of consciousness acted as recruiters and solicited professional peers with diverse perspectives from five countries (Canada, Italy, Netherlands, United Kingdom, and United States) to participate in the study. Patient advocates were identified through their current or former participation in research programs at Western University, Canada. 
Table 1 Domains identified from scoping review of existing quality-of-life instruments

\begin{tabular}{|c|c|}
\hline Domain & Definition of domain \\
\hline \multicolumn{2}{|l|}{ Physical } \\
\hline 1. Somatic complaints & $\begin{array}{l}\text { Any physical symptoms one may be experiencing that would negatively affect one's physical } \\
\text { health }\end{array}$ \\
\hline 2. Communication capacity & One's ability to articulate one's thoughts through speech (includes language comprehension) \\
\hline 3. Bodily pain and discomfort & A noxious or unpleasant sensation in the body that one can experience due to injury or illness \\
\hline 4. Physical functioning & The perception one has about one's physical ability to move freely and with ease \\
\hline 5. Performing activities of daily living & $\begin{array}{l}\text { Ability to perform six actions daily without assistance: eating, bathing, dressing, toileting, } \\
\text { walking, and continence }\end{array}$ \\
\hline 6. Self-care & Intentional actions taken to look after oneself and one's physical health. \\
\hline 7. Vitality & The level of energy one has to get through daily activities \\
\hline 8. Issues sleeping & $\begin{array}{l}\text { Any problem one may have getting adequate rest because of trouble falling asleep, staying } \\
\text { asleep, or waking up prematurely }\end{array}$ \\
\hline 9. Physical senses & One's experience with vision, hearing, taste, smell, and touch \\
\hline 10. Sexual activity & One's engagement in activities associated with sexual intercourse \\
\hline 11. Physical appearance & The perception of one's physical characteristics and external features \\
\hline \multicolumn{2}{|l|}{ Mental } \\
\hline 12. Experiencing anxiety & Negative feelings of panic, worry, fear and nervousness that one may be experiencing \\
\hline 13. Experiencing depression & Negative feelings of sadness, hopelessness, discouragement, and overall disinterest in life \\
\hline 14. Experiencing negative emotions & $\begin{array}{l}\text { A range of unpleasant feelings that can be evoked (for example, distress, frustration, resent, } \\
\text { stress, etc.) }\end{array}$ \\
\hline 15. Experiencing positive emotions & $\begin{array}{l}\text { A range of pleasant feelings that can be evoked (for example, contentment, happiness, satis- } \\
\text { faction, appreciation, etc.) }\end{array}$ \\
\hline 16. Cognitive functioning & One's ability to memorize, learn, comprehend, and understand information. \\
\hline 17. Self-acceptance & One's ability to like oneself in light of one's limits, failures, and circumstances \\
\hline 18. Self-esteem & The value one places on one's worth and capabilities \\
\hline 19. Sense of identity & $\begin{array}{l}\text { The concept that one has of oneself, which can evolve over the course of one's life. It is } \\
\text { closely related to how people see and define themselves }\end{array}$ \\
\hline 20. Ability to cope & $\begin{array}{l}\text { One's capacity to manage and overcome difficult situations and regulate one's unpleasant } \\
\text { emotions }\end{array}$ \\
\hline 21. Experiencing loneliness & $\begin{array}{l}\text { The feeling of being alone or isolated from others. It can also be the feeling of having been } \\
\text { rejected by others. }\end{array}$ \\
\hline 22. Perception of one's health & $\begin{array}{l}\text { One's health refers to the positive and/or negative opinion or attitude one has about one's } \\
\text { overall health }\end{array}$ \\
\hline 23. Positive future outlook & $\begin{array}{l}\text { Feeling that one's life is heading in a good direction and one is striving towards positive } \\
\text { outcomes }\end{array}$ \\
\hline 24. Appreciation of life & Being grateful for the life one has and deeming one's existence as meaningful. \\
\hline \multicolumn{2}{|l|}{ Social } \\
\hline 25. Social functioning & The level of interpersonal interactions with one's environment. \\
\hline 26. Social support & The physical and emotional comfort that one gives or receives from one's personal network \\
\hline 27. Personal relationships & Having close positive connections with other people \\
\hline 28. Relationship with family & $\begin{array}{l}\text { The close interaction and level of satisfaction one has with family members including } \\
\text { spouses }\end{array}$ \\
\hline \multicolumn{2}{|l|}{ Psychosocial } \\
\hline 29. Spirituality & $\begin{array}{l}\text { One's search for meaning in life events and desire for connectedness to the universe and/or } \\
\text { some higher power. }\end{array}$ \\
\hline 30. Sense of belonging & The feeling that one is a member of something without discrimination or stigmatization \\
\hline 31. Community integration & The opportunity to reside in a community and participate fully in aspects of community life \\
\hline 32. Limitations in life roles & $\begin{array}{l}\text { The inability to fulfill one's prescribed or expected responsibilities. This inability could be } \\
\text { the result of physical or emotional problems }\end{array}$ \\
\hline 33. Autonomy and independence & $\begin{array}{l}\text { The perception and actuality that one has freedom to make one's decisions, without being } \\
\text { pressured }\end{array}$ \\
\hline 34. Safety and security & The perception one is free from harm or danger \\
\hline
\end{tabular}


Table 1 (continued)

\begin{tabular}{|c|c|}
\hline Domain & Definition of domain \\
\hline \multicolumn{2}{|l|}{ Economic } \\
\hline 35. Satisfaction with financial resources & The level of contentment one has with one's total income, assets, and wealth \\
\hline 36. Satisfaction with employment & The level of contentment one has with one's occupation \\
\hline \multicolumn{2}{|l|}{ Other } \\
\hline 37. Pursuit of goals & One's continued motivation to achieve personal aims or desires \\
\hline 38. Satisfaction with living conditions & $\begin{array}{l}\text { The level of contentment one has about one's living environment, including standard of liv- } \\
\text { ing }\end{array}$ \\
\hline 39. Satisfaction with daily activities & $\begin{array}{l}\text { The level of contentment one has with hobbies, recreational activities, and responsibilities } \\
\text { one participates in daily }\end{array}$ \\
\hline 40. Satisfaction with medical treatment/services & $\begin{array}{l}\text { The level of contentment one has with the quantity and quality of care one receives for one's } \\
\text { medical condition. Additionally, it includes any restriction or hardship one may experience } \\
\text { when seeking care and the imposition this poses on one's life }\end{array}$ \\
\hline 41. Effects of medication & $\begin{array}{l}\text { Any positive and/or negative results of taking medications for one's ailment(s). This can } \\
\text { include adverse effects and symptom relief }\end{array}$ \\
\hline \multicolumn{2}{|l|}{ Overall quality of life } \\
\hline 42. Overall quality of life & $\begin{array}{l}\text { The broad satisfaction one has about one's life taking all aspects of well-being into considera- } \\
\text { tion }\end{array}$ \\
\hline
\end{tabular}

All nominated experts who expressed interest in participating were emailed a letter of information about the study, an informational package about relevant literature on patients who are behaviourally nonresponsive and covertly aware, and an overview of the Delphi process prior to receiving the first survey.

\section{First-round survey and procedure}

The first-round online survey in the Delphi process contained the 42 domains of QoL identified through the scoping review. The domains were organized into the following categories in the survey: physical, mental, social, psychosocial, economic, overall QoL, and other. Close-ended questions (offering a set of response options from which to choose) were predominantly employed; the use of many open-ended questions in the first round of a Delphi process has been shown to be unduly demanding of experts [16].

Participants were asked to rate the importance, on a scale of 1 (not important) to 4 (very important), of each domain for inclusion in a QoL instrument for patients who are behaviourally nonresponsive and covertly aware. At the end of the survey, an open-ended question invited experts to suggest any domains, missing from the list identified by the scoping review.

\section{First-round analyses}

Domains were classified into three outcomes based on median score: (i) consensus that the domain is important for inclusion in an instrument to assess QoL in patients who are behaviourally nonresponsive and covertly aware (median =4); (ii) consensus that the domain is not important (median $=1)$; (iii) no consensus reached on the domain $(1<$ median $<4)$.

Three researchers reviewed and considered additional domains suggested by experts in the final question of the first-round survey. Collectively, they determined whether a suggested domain was novel, in which case domain name and description were generated for inclusion in the second round.

\section{Second-round survey and procedure}

The second-round survey included domains on which consensus was not reached in first round and the newly added domains suggested by the experts.

Participants were instructed to rate the list of remaining domains, on a 7-point scale from 1 (not at all important) to 7 (extremely important). As per Delphi Method convention, participants were unable to suggest any further novel domains during this round [14].

\section{Second-round analyses}

Similar to round one, median scores were calculated for each domain. The increase in the number of response options, from 4 to 7, allowed for more variance and a semi-interquartile range (SIR) analysis. The domains were classified again into three outcomes: (i) consensus that the domain is important (SIR $\leq 1$ and median $>5$ ); (ii) consensus that the domain is not important ( $\mathrm{SIR} \leq 1$ and median $\leq 5$ ); (iii) no consensus on the importance of the on domain (SIR $>1)$. 


\section{Third-round survey and procedure}

The third-round survey included the domains of QoL on which consensus was not reached during the second round. Participants were instructed to rate the domains on the same seven-point scale used in the former round. Additionally, experts were asked in a final question to select and rank the five domains of QoL they believed to be the most important for inclusion in a QoL instrument for patients who are behaviourally nonresponsive and covertly aware. The list of domains included all of those from round one, two domains on which experts had reached consensus in round two, and all domains from round three. Participants were instructed to order their list of five domains on a scale of importance with (1) being the most important and (5) being the least important.

\section{Third-round analyses}

Similar to round two, SIR and median scores were calculated for each domain on the third survey. For the ranking question, a mean rank score was generated for the five domains of QoL each expert selected. Domains rated as being the most important (ranked number 1) were coded as 5, domains ranked number 2 were coded as 4 , and so on.

Pre-specified subgroup analyses were conducted to reveal whether there were differences in the rating of domains by type of expert group. The expert panel was split into two groups, patient advocates and professionals (healthcare personnel, quality-of-life methodologists, bioethicists, and neuroscientists), based on the nature of their relationship to behaviourally nonresponsive and covertly aware patients. Patient advocates are more likely to have a close personal relationship with patients while the professionals do not. The first subgroup analysis examined whether patient advocates rated domains that were categorized as unimportant and, ultimately, eliminated differently than the professionals. This was done by calculating, separately, for each group, the median and SIR for each domain eliminated. The second subgroup analysis examined which domains patient advocates selected and ranked as part of their top five domains for inclusion in a QoL instrument compared with the professionals. This was done by calculating, separately for each group, the mean rank score for each selected and ranked domain.

\section{Results}

\section{Respondents}

Forty-two experts were nominated as potential participants and were contacted about the study. Of those, 37 experts expressed interest and were emailed the letter of information and the study background package. 35 individuals (83\% recruitment rate) provided consent to participate in the study, including seven healthcare professionals; seven quality-oflife methodologists; six bioethicists; seven neuroscientists; and eight patient advocates.

\section{First-round results}

The first survey was completed by 35 experts ( $95 \%$ response rate). In the first round, consensus was reached on 16 of the 42 domains: 13 were deemed to be very important and 3 were deemed to be less important (Table 2). The remaining 26 domains for which consensus was not reached were moved to the second round for re-rating. Nine potential new domains were suggested during the first round. Two of these, "feeling respected" and "esthetic capacity," were evaluated as novel and moved to the second round.

\section{Second-round results}

The second survey was completed by 34 experts (97\% response rate); only those who completed the first survey were sent the second and third. In the second round, consensus was reached on 17 of the 28 domains: nine domains were deemed to be important, while 8 domains were considered to be of less importance (Table 2). Consensus was not reached on the remaining 11 domains, which were moved to the third round.

\section{Third-round results}

The third survey was completed by 33 experts ( $94 \%$ response rate) and consensus was reached on only one domain (Table 2). Over the three rounds, experts reached consensus on 34 domains: 22 domains were rated as being important and 12 domains were deemed to be of less importance. A top ten list of domains was compiled from the experts' list of the 5 most important domains identified in the previous three rounds according to mean rank score (Table 3 ).

\section{Subgroup analyses results}

The first subgroup analysis examined whether patient advocates rated domains as being of lesser importance than did professionals (Table 4). 12 domains were considered to be unimportant for assessing QoL in patients who are behaviourally nonresponsive and covertly aware and were thus eliminated by the full panel. Analyzing the responses of patient advocates and professionals separately revealed disagreement on the importance of 3 of the 12 eliminated domains. Professionals reached consensus that the domain "cognitive functioning" was important (median $=6.0$, SIR $=0.5$ ), but patient advocates rated this domain as lacking 
Table 2 Median and semiinterquartile range (SIR) values from each Delphi round

\begin{tabular}{|c|c|c|c|c|c|}
\hline \multirow[t]{2}{*}{ Domain } & \multirow{2}{*}{$\begin{array}{l}\text { First round }^{\mathrm{a}} \\
\text { Median }\end{array}$} & \multicolumn{2}{|c|}{ Second round } & \multicolumn{2}{|c|}{ Third round } \\
\hline & & Median & SIR & Median & SIR \\
\hline \multicolumn{6}{|l|}{ Physical } \\
\hline 1. Somatic complaints & $4.0^{*}$ & - & - & - & - \\
\hline 2. Communication capacity & $4.0^{*}$ & - & - & - & - \\
\hline 3. Bodily pain and discomfort & $4.0^{*}$ & - & - & - & - \\
\hline 4. Physical functioning & 3.0 & 5.0 & 1.5 & 3.0 & 1.5 \\
\hline 5. Performing activities of daily living & 3.0 & 4.5 & 1.9 & 2.0 & 1.5 \\
\hline 6. Self-care & 3.0 & 4.0 & 1.5 & 2.0 & 1.5 \\
\hline 7. Vitality & 2.0 & $5.0^{*}$ & 0.9 & - & - \\
\hline 8. Issues sleeping & 3.0 & $5.5^{*}$ & 0.5 & - & - \\
\hline 9. Physical senses & 3.0 & $6.0^{*}$ & 0.5 & - & - \\
\hline 10. Sexual activity & $1.0^{*}$ & - & - & - & - \\
\hline 11. Physical appearances & 2.0 & 4.0 & 1.5 & 3.0 & 1.5 \\
\hline \multicolumn{6}{|l|}{ Mental } \\
\hline 12. Experiencing anxiety & $4.0^{*}$ & - & - & - & - \\
\hline 13. Experiencing depression & $4.0^{*}$ & - & - & - & - \\
\hline 14. Experiencing negative emotions & $4.0^{*}$ & - & - & - & - \\
\hline 15. Experiencing positive emotions & $4.0^{*}$ & - & - & - & - \\
\hline 16. Cognitive functioning & 3.0 & $5.0^{*}$ & 0.5 & - & - \\
\hline 17. Self-acceptance & 3.0 & $5.5^{*}$ & 1.0 & - & - \\
\hline 18. Self-esteem & 3.0 & $6.0^{*}$ & 0.5 & - & - \\
\hline 19. Sense of identity & 3.0 & 5.5 & 1.4 & $5.0^{*}$ & 1.0 \\
\hline 20. Ability to cope & 3.0 & $6.0^{*}$ & 1.0 & - & - \\
\hline 21. Experiencing loneliness & $4.0^{*}$ & - & - & - & - \\
\hline 22. Perception of one's health & 3.0 & $5.0^{*}$ & 1.0 & - & - \\
\hline 23. Positive future outlook & 3.0 & $5.0^{*}$ & 0.9 & - & - \\
\hline 24. Appreciation of life & 3.0 & $6.0^{*}$ & 0.9 & - & - \\
\hline \multicolumn{6}{|l|}{ Social } \\
\hline 25. Social functioning & 3.0 & $5.0^{*}$ & 0.5 & - & - \\
\hline 26. Social support & 3.0 & $6.0^{*}$ & 0.5 & - & - \\
\hline 27. Personal relationships & $4.0^{*}$ & - & - & - & - \\
\hline 28. Relationships with family & $4.0^{*}$ & - & - & - & - \\
\hline \multicolumn{6}{|l|}{ Psychosocial } \\
\hline 29. Spirituality & 2.0 & 4.0 & 1.9 & 4.0 & 2.0 \\
\hline 30. Sense of belonging & 2.0 & 4.0 & 2.0 & 4.0 & 1.5 \\
\hline 31. Community integration & 2.0 & 4.0 & 1.5 & 4.0 & 1.5 \\
\hline 32. Limitations in life roles & 2.0 & $4.0^{*}$ & 1.0 & - & - \\
\hline 33. Autonomy and independence & 3.0 & $6.0^{*}$ & 1.0 & - & - \\
\hline 34. Safety and security & 3.0 & $5.0^{*}$ & 1.0 & - & - \\
\hline \multicolumn{6}{|l|}{ Economic } \\
\hline 35. Satisfaction with financial resources & $1.0^{*}$ & - & - & - & - \\
\hline 36. Satisfaction with employment & $1.0^{*}$ & - & - & - & - \\
\hline \multicolumn{6}{|l|}{ Other } \\
\hline 37. Pursuit of goals & 3.0 & 3.5 & 1.5 & 5.0 & 2.0 \\
\hline 38. Satisfaction with living conditions & 3.0 & $5.0^{*}$ & 1.0 & - & - \\
\hline 39. Satisfaction with daily activities & 3.0 & 5.0 & 1.5 & 5.0 & 1.5 \\
\hline 40. Satisfaction with medical treatment/services & $4.0^{*}$ & - & - & - & - \\
\hline 41. Effects of medication & $4.0^{*}$ & - & - & - & - \\
\hline \multicolumn{6}{|l|}{ Overall quality of life } \\
\hline 42. Overall quality of life & $4.0^{*}$ & - & - & - & - \\
\hline \multicolumn{6}{|l|}{ Domains suggested by experts } \\
\hline 43. Esthetic capacity & - & 5.0 & 1.5 & 5.0 & 1.5 \\
\hline 44. Feeling respected & - & $6.0^{*}$ & 1.0 & - & - \\
\hline
\end{tabular}


Table 2 (continued)

Table 3 Highest ranked domains by expert groups during the third Delphi round
*Consensus was reached

${ }^{a}$ In the first round, domains were rated on a 4-point scale, but in subsequent rounds the ratings were on a 7-point scale

\begin{tabular}{|c|c|c|c|c|}
\hline Expert group & Rank & Domain & $\begin{array}{l}\text { Appearance } \\
\text { count }^{\mathrm{a}}\end{array}$ & Mean rank score \\
\hline \multirow[t]{10}{*}{ Expert panel $(N=33)$} & 1 & Bodily pain and discomfort & 20 & 2.45 \\
\hline & 2 & Communication capacity & 19 & 1.67 \\
\hline & 3 & Overall quality of life & 14 & 1.42 \\
\hline & 4 & Somatic complaints & 10 & 1.18 \\
\hline & 5 & Personal relationships & 13 & 0.94 \\
\hline & 6 & Experiencing negative emotions & 9 & 0.91 \\
\hline & 7 & Relationship with family & 8 & 0.70 \\
\hline & 8 & Experiencing positive emotions & 7 & 0.55 \\
\hline & 9 & Feeling respected & 6 & 0.55 \\
\hline & 10 & Ability to cope & 6 & 0.52 \\
\hline \multirow[t]{5}{*}{ Patient advocates $(N=7)$} & 1 & Communication capacity & 4 & 1.57 \\
\hline & 2 & Feeling respected & 3 & 1.57 \\
\hline & 2 & Sense of belonging & 3 & 1.57 \\
\hline & 4 & Relationship with family & 4 & 1.43 \\
\hline & 5 & Bodily pain and discomfort & 3 & 1.43 \\
\hline \multirow[t]{5}{*}{ Professionals $(N=26)$} & 1 & Bodily pain and discomfort & 17 & 2.73 \\
\hline & 2 & Communication capacity & 15 & 1.69 \\
\hline & 3 & Overall quality of life & 13 & 1.65 \\
\hline & 4 & Somatic complaints & 9 & 1.35 \\
\hline & 5 & Personal relationships & 11 & 1.04 \\
\hline
\end{tabular}

${ }^{a}$ Number of times a particular domain appeared in the expert's top five ranking

\begin{tabular}{|c|c|c|c|c|c|c|}
\hline \multirow[t]{2}{*}{ Domain } & \multicolumn{3}{|c|}{ Median } & \multicolumn{3}{|c|}{ Semi-interquartile range (SIR) } \\
\hline & Panel & $\begin{array}{l}\text { Patient } \\
\text { advo- } \\
\text { cates }\end{array}$ & Professionals & Panel & $\begin{array}{l}\text { Patient } \\
\text { advo- } \\
\text { cates }\end{array}$ & Professionals \\
\hline Sexual activity & 1.0 & 1.0 & 2.0 & $\mathrm{n} / \mathrm{a}$ & $\mathrm{n} / \mathrm{a}$ & $\mathrm{n} / \mathrm{a}$ \\
\hline Satisfaction with financial resources & 1.0 & 2.5 & 1.0 & $\mathrm{n} / \mathrm{a}$ & $\mathrm{n} / \mathrm{a}$ & $\mathrm{n} / \mathrm{a}$ \\
\hline Satisfaction with employment & 1.0 & 3.0 & 1.0 & $\mathrm{n} / \mathrm{a}$ & $\mathrm{n} / \mathrm{a}$ & $\mathrm{n} / \mathrm{a}$ \\
\hline Vitality & 5.0 & 5.0 & 5.0 & 0.9 & 1.0 & 0.9 \\
\hline cognitive functioning & 5.0 & 5.0 & 6.0 & 0.5 & 0.8 & 0.5 \\
\hline Perception of one's health & 5.0 & 5.0 & 5.0 & 1.0 & 0.6 & 1.0 \\
\hline Positive future outlook & 5.0 & 6.5 & 5.0 & 0.9 & 0.9 & 0.9 \\
\hline Social functioning & 5.0 & 5.5 & 5.0 & 0.5 & 0.5 & 0.5 \\
\hline Limitations in life roles & 4.0 & 4.5 & 4.0 & 1.0 & 1.1 & 1.0 \\
\hline Safety and security & 5.0 & 6.0 & 5.0 & 1.0 & 1.1 & 0.5 \\
\hline Satisfaction with living conditions & 5.0 & 6.0 & 5.0 & 1.0 & 1.4 & 1.0 \\
\hline Sense of identity & 5.0 & 5.0 & 5.0 & 1.0 & 0.5 & 1.0 \\
\hline
\end{tabular}

Emboldened values indicate domains for which the subgroups reached a differing consensus of importance 
importance (median $=5.0, \mathrm{SIR}=0.8)$. Additionally, patient advocates reached consensus that the domains "positive future outlook" and "social functioning" have importance, while the professionals deemed these to be of lesser importance. Furthermore, patient advocates were unable to reach consensus (SIR > 1) on the following domains: "limitations in life roles," "safety and security," and "satisfaction with living conditions."

The second subgroup analysis examined which domains patient advocates selected and ranked as part of their top five domains for inclusion in a QoL instrument (Table 3). While both patient advocates and professionals selected two domains, "bodily pain and discomfort" and "communication capacity," as a part of their top five domains, the former rated "feeling respected" and "sense of belonging" considerably higher than the latter.

\section{Discussion}

The aim of the study was to begin the process of developing an instrument to measure QoL in patients who are behaviourally nonresponsive and covertly aware and can communicate with the aid of fMRI technologies. Due to the nature of the injuries sustained by these individuals, conventional QoL measurement development techniques are not applicable. Therefore, this study utilized innovative methods to generate the foundational knowledge needed to determine the most relevant domains for evaluating $\mathrm{QoL}$ in this unique subset of patients. Specifically, the combination of a scoping review of existing QoL instruments used in patient populations in some ways similar to behaviourally nonresponsive and covertly aware individuals and a three-round Delphi consensus process with an expert panel was used.

The scoping review identified 42 unique domains of $\mathrm{QoL}$ from existing instruments that were used to generate the first Delphi survey for expert input. Only two new domains were added based on recommendations from experts in the first round, suggesting that the scoping review identified a reasonably comprehensive list of domains. During the three Delphi rounds, experts reached consensus on more than three quarters of the 44 domains (42 identified from the scoping review and 2 added based on suggestion by experts): 22 domains were rated as being important and 12 domains were deemed to be of less importance. The high degree of consensus is not surprising as the domains come from existing instruments that are used to assess patient QoL. A list of the highest ranked domains was produced and included "bodily pain and discomfort," "communication capacity," "overall quality of life," "somatic complaints," and "personal relationships." The highest ranked domain, "bodily pain and discomfort," is in line with previous research findings that show that "bodily pain and discomfort" is given great weight in many QoL evaluation tools [17].

The subgroup analyses comparing the responses of patient advocates and professionals (healthcare personnel, neuroscientists, bioethicists, and quality-of-life methodologists) showcased both similarities and differences in responses. The two groups differed in their rating of only three of the 12 domains that were deemed to lack importance over the Delphi rounds. Two of the domains, "positive future outlook" and "social functioning" were rated as being important by patient advocates but not by professionals. This might suggest that families tended to emphasize social aspects of well-being, including seeing patients as persons with valuable futures. Conversely, professionals regarded the domain "cognitive functioning" as being highly important, but patient advocates did not. Both groups included the domains "bodily pain and discomfort" and "communication capacity" among their 5 highest ranked domains. Additionally, professionals ranked "personal relationships" highly, while patient advocates selected "relationship with family" more often. However, these two domains can be thought of as overlapping. Thus, despite the apparent differences in the expert groups, there was a high degree of consistency in their responses.

The findings presented here need to be considered with the context of its limitations. The study design did not allow for the patient advocates and professionals to engage in a direct dialogue to explain their views on domains of QoL. These qualitative data could have provided the research team insight into the underlying rationale for consensus or disagreement.

There are also some recognized limitations with the Delphi technique. First, both the Delphi process and its outcomes are subjective. Consensus reached on a set of items does not equate with true or correct answers. Indeed, the domains selected based on expert opinion may not be what patients would select for themselves. Due to convenience sampling, the judgments of this expert panel may not be representative of all experts who were qualified to participate in this study. Second, although scoring cut-offs were preestablished in this study, consensus cut-offs in Delphi studies are somewhat arbitrary. Different Delphi studies use various levels of agreement to quantify consensus among their panel of experts. The results of this study may be altered if a different approach to consensus scoring was adopted.

It remains to be determined how covertly aware patients perceive their circumstances and QoL after suffering a life-altering injury. Nonetheless, it is important that any dialogue on what constitutes a life worth living should give due consideration to the lived experience of patients. Where possible, quality of life should be a central patient-reported outcome that informs these discussions. Assessing QoL in this population is needed if health care 
professionals and caregivers are to do more to enhance care provided, and to provide families insight into how their loved ones are faring and the extent to which they are satisfied with their existence. Neuroimaging techniques and brain-computer interfaces have the potential to provide an opportunity to give patients who are behaviourally nonresponsive and covertly aware a "voice" to directly report on their lived experience. Furthermore, the novel methods used here may be adapted to inform the development of QoL instruments for other patients with profound communication impairments, including those associated with progressive neurological disease or congenital disabilities, that make using conventional QoL measurement development processes impractical.

The development of a QoL instrument is a multistage process and this study was only the first step towards evaluating QoL in patients who are behaviourally nonresponsive and covertly aware. The findings from this study will aid interested research teams in undertaking the additional work required to create a validated QoL instrument that can be administered to patients using a brain-computer interface [7, 18]. Since the conceptualization and completion of this study, further technological advances have occurred in neuroimaging and brain-computer interfaces. Discussions need to occur among neuroscientists to determine: how many questions can be reasonably and reliably asked of patients in an fMRI scanning session; and, if new paradigms could be created to expand the number of response options from binary to accommodate Likerttype scales. After these issues are addressed, a selection of domains can be made, and specific questions can be drafted for an instrument.

Acknowledgements We would like to thank the members of the expert panel for lending their time and expertise, and without whom this work would not have been possible. Members of the expert panel included Salman Abbasi (Patient and Family Advisor), Ruth Barclay (University of Manitoba), John Gordon Boyd (Queens University), Linda Bruni (Patient and Family Advisor), Srivas Chennu (University of Kent), Joyce Cramer (Yale University), Damian Cruse (University of Birmingham), Athena Demertzi (University of Liège), David Feeny (McMaster University), Brian Feldman (University of Toronto), Davina Fernández-Espejo (University of Birmingham), Paola Finoia (Cambridge University), Teneille Gofton (Western University), Mackenzie Graham (Oxford University), Jennifer Hawkins (Duke University), Gil Hersch (George Mason University), Terry Howard (Patient and Family Advisor), Guy Kahane (Oxford University), Nadira King (Patient and Family Advisor), Ayse Kuspinar (University of Waterloo), Marcello Massimini (University of Milan), Nancy Mayo (McGill University), Lorina Naci (Trinity College Dublin), Margarita Perez (Patient and Family Advisor), Andrew Peterson (George Mason University), Leonard Rodrigues (Patient and Family Advisor), Keith Sequeira (Western University), Anthony Skelton (Western University), Jeanne Teitelbaum (University of Montreal), Juan Torres (Patient and Family Advisor), Andrea Townson (University of British Columbia), Paul and Jeff Tremblay (Patient and Family Advisor), Alexis Turgeon (Université de Laval), Samuel Wiebe (University of Calgary), and Bryan Young (Western University).
Funding This project was funded by an operating grant from the Canadian Institutes of Health Research (MOP-133705).

\section{Compliance with ethical standards}

Conflict of interest Charles Weijer receives consulting income from Eli Lilly \& Company Canada. The other authors have no competing interests to declare.

Ethical approval Approval for this study was obtained from the Western University Health Science Research Ethics Board (\#108066). Informed consent was obtained from all participants included in this study.

\section{References}

1. Maas, A. I., et al. (2017). Traumatic brain injury: Integrated approaches to improve prevention, clinical care, and research. The Lancet Neurology, 16(12), 987-1048.

2. Gean, A. D., \& Fischbein, N. J. (2010). Head trauma. Neuroimaging Clinics, 20(4), 527-556.

3. Greenwald, B., \& Nori, P. (1995). Disorders of consciousness. Manual of Traumatic Brain Injury Management, 1, 199.

4. Payne, K., et al. (1996). Physicians' attitudes about the care of patients in the persistent vegetative state: a national survey. Annals of Internal Medicine, 125(2), 104-110.

5. Laureys, S., Owen, A. M., \& Schiff, N. D. (2004). Brain function in coma, vegetative state, and related disorders. The Lancet Neurology, 3(9), 537-546.

6. Owen, A. M., et al. (2006). Detecting awareness in the vegetative state. Science, 313(5792), 1402.

7. Monti, M. M., et al. (2010). Willful modulation of brain activity in disorders of consciousness. New England Journal of Medicine, 362(7), 579-589.

8. Fernández-Espejo, D., \& Owen, A. M. (2013). Detecting awareness after severe brain injury. Nature Reviews Neuroscience, 14(11), 801.

9. Naci, L., \& Owen, A. M. (2013). Making every word count for nonresponsive patients. JAMA Neurology, 70(10), 1235-1241.

10. Kondziella, D., et al. (2016). Preserved consciousness in vegetative and minimal conscious states: Systematic review and metaanalysis. Journal of Neurology, Neurosurgery and Psychiatry, 87(5), 485-492.

11. WHOQOL Group. (1995). The World Health Organization quality of life assessment (WHOQOL): Position paper from the World Health Organization. Social Science and Medicine, 41(10), 1403-1409.

12. Pietersma, S., de Vries, M., \& van den Akker-van, M. E. (2014). Domains of quality of life: Results of a three-stage Delphi consensus procedure among patients, family of patients, clinicians, scientists and the general public. Quality of Life Research, 23(5), 1543-1556.

13. Keeney, S., McKenna, H., \& Hasson, F. (2010). The Delphi technique in nursing and health research. Hoboken: Wiley.

14. Hsu, C.-C., \& Sandford, B. A. (2007). Minimizing non-response in the Delphi process: How to respond to non-response. Practical Assessment, Research \& Evaluation, 12(17), 62-78.

15. Borgiel, A. E., et al. (1989). Recruiting family physicians as participants in research. Family Practice, 6(3), 168-172.

16. Skulmoski, G. J., Hartman, F. T., \& Krahn, J. (2007). The Delphi method for graduate research. Journal of Information Technology Education: Research, 6, 1-21. 
17. Skevington, S. M. (1998). Investigating the relationship between pain and discomfort and quality of life, using the WHOQOL. Pain, 76(3), 395-406.

18. Naci, L., et al. (2012). Brain-computer interfaces for communication with nonresponsive patients. Annals of Neurology, 72(3), 312-323.
Publisher's Note Springer Nature remains neutral with regard to jurisdictional claims in published maps and institutional affiliations. 